University of Nebraska - Lincoln

DigitalCommons@University of Nebraska - Lincoln

Agronomy \& Horticulture - Faculty Publications

Agronomy and Horticulture Department

1999

\title{
Ecophysiological characteristics of four maize hybrids and Abutilon theophrasti
}

John L. Lindquist

University of Nebraska-Lincoln, jlindquist1@unl.edu

David A. Mortensen

University of Nebraska-Lincoln

Follow this and additional works at: https://digitalcommons.unl.edu/agronomyfacpub

Part of the Plant Sciences Commons

Lindquist, John L. and Mortensen, David A., "Ecophysiological characteristics of four maize hybrids and Abutilon theophrasti" (1999). Agronomy \& Horticulture -- Faculty Publications. 509.

https://digitalcommons.unl.edu/agronomyfacpub/509

This Article is brought to you for free and open access by the Agronomy and Horticulture Department at DigitalCommons@University of Nebraska - Lincoln. It has been accepted for inclusion in Agronomy \& Horticulture -Faculty Publications by an authorized administrator of DigitalCommons@University of Nebraska - Lincoln. 


\title{
Ecophysiological characteristics of four maize hybrids and Abutilon theophrasti
}

\author{
J. L. Lindquist and D. A. Mortensen \\ Department of Agronomy, University of Nebraska-Lincoln, Lincoln NE, USA \\ Corresponding author - J. L. Lindquist, email jlindquist@unl.edu
}

\begin{abstract}
Combining empirical research with simulation modeling may improve our understanding of the dynamics of crop:weed competition and for testing hypotheses on the importance of specific traits for enhancing crop performance in mixtures. Two field experiments were conducted to quantify and compare estimates of traits important for radiation interception and utilization in four maize hybrids and Abutilon theophrasti grown in monoculture. Early leaf area growth rate did not vary among maize hybrids within a year, but varied among years. The response of $\mathrm{CO}_{2}$ assimilation rate to absorbed radiation and leaf nitrogen content did not differ among hybrids. Abutilon theophrasti and two old maize hybrids partitioned more new biomass to stem relative to reproductive organs than newer hybrids. Old hybrids had greater specific leaf area during the period of most rapid growth, grew taller, and leaf area was distributed higher in their canopy. Extinction coefficients for diffuse radiation did not differ among hybrids or between years. Results suggest that these four maize hybrids may differ in their ability to intercept incident radiation, which may influence their ability to compete for light.
\end{abstract}

Keywords: modeling, competition, Abutilon theophrasti, growth analysis

\section{Introduction}

Maize (Zea mays L.) is economically the most important row crop produced in the USA (Bridges, 1992). Thirty-seven per cent of arable land in Nebraska is planted with maize, $72 \%$ of which is irrigated (Nelson et al., 1993). Abutilon theophrasti Medik. (velvetleaf) is one of the most troublesome weeds in maize throughout the USA (Bridges, 1992). Under irrigated and high nitrogen input conditions, competition for light is a primary cause of yield loss because of $A$. theophrasti.

Light is a resource that cannot be stored. In terms of its use for plant growth, a photon not absorbed by a plant is lost. Competition for light is therefore an instantaneous process that depends on the relative share of available light that is absorbed by a species in 
a mixed canopy and the efficiency of energy conversion into dry matter (Lawlor, 1995). Light interception by each species in mixed canopies is determined by the leaf area index (LAI), plant height, vertical leaf area distribution and leaf angle distribution (Sinoquet \& Caldwell, 1995). Although competition for light is instantaneous, its outcome can only be determined by integration of carbon assimilation within the canopy over the entire growing season. Measurement of all relevant factors throughout a canopy and the plant growth period is impractical. Combining periodic measurements of important canopy traits with an ecophysiological model may be helpful for improving our understanding of the dynamics of crop:weed competition (Cousens, 1996) and for testing hypotheses on the importance of specific traits to crop performance in crop:weed mixtures (Lindquist \& Mortensen, 1997).

A number of simulation models have been developed recently in which the mechanisms of interplant competition are described based on plant physiology (see Caldwell et al., 1996). Kropff \& van Laar (1993) developed INTERCOM to simulate sugar beet (Beta vulgaris L.)-Chenopodium album L. (fat hen or lambsquarters) competition for light and soil water in the Netherlands. INTERCOM was later modified to simulate rice (Oryza sativa L.):Echinochloa crus-galli (L.) Beauv. competition for light in the Philippines (Kropff et al., 1994). INTERCOM simulates competition for light using parameter estimates that characterize the phenological development and morphology of each competing species (Kropff \& van Laar, 1993). Many of these parameter estimates may vary among crop genotypes, species and cultural practices. The objectives of this research were to compare estimates of these parameters for four morphologically different maize hybrids and A. theophrasti, and to compare potential competitiveness for light of these hybrids.

\section{Phenological development and morphological parameters}

INTERCOM uses a dimensionless scale to define phenological development stage, where 0 is assigned at seedling emergence, 1 at anthesis and 2 at physiological maturity (Kropff \& Spitters, 1992). Leaf area expansion is often exponential during early phases of plant growth (Kropff, 1993). Early leaf area growth rate (RGRL) can be quantified by regressing observed $\ln (\mathrm{LAI})$ on day degrees accumulated from emergence (temperature sum). The intercept represents $\ln \left(\mathrm{LAI}_{\mathrm{o}}\right)$, where $\mathrm{LAI}_{\mathrm{o}}$ is apparent LAI at emergence, and the slope is RGRL. Relationship between instantaneous $\mathrm{CO}_{2}$ assimilation rate $\left(C_{\mathrm{A}}\right)$ and photosynthetic photon flux density (PPFD) can be quantified using a two-parameter hyberbolic equation (Goudriaan, 1982). The two parameters include the light use efficiency as PPFD approaches zero $(\varepsilon)$ and the light-saturated $C_{\mathrm{A}}\left(A_{\mathrm{m}}\right)$. Light-saturated $C_{\mathrm{A}}\left(A_{\mathrm{m}}\right)$ is dependent upon the amount of chlorophyll per unit leaf area and varies considerably as a function of leaf age and environmental conditions during growth (Sinclair \& Horie, 1989). The amount of chlorophyll can be estimated based on leaf nitrogen content $\left(N_{L^{\prime}}, \mathrm{kg} \mathrm{N}\right.$ ha leaf ${ }^{-1}$ ). INTERCOM for rice:E. crus-galli competition used a linear relationship to estimate $A_{\mathrm{m}}$ from leaf nitrogen content (Lindquist \& Kropff, 1996). Sinclair \& Horie (1989) showed that this relationship is non-linear for maize and presented a functional relationship to account for this. Their approach was incorporated into INTERCOM using:

$$
A_{\mathrm{m}}=A_{\max }\left(\frac{2}{1+\exp \left(-\mathrm{a}\left(N_{\mathrm{L}}-\mathrm{b}\right)\right)}\right)
$$


where $\mathrm{a}$ and $\mathrm{b}$ are shape coefficients and $A_{\max }$ is the maximum rate of $\mathrm{CO}_{2}$ assimilation possible during the life of the plant.

Net daily growth $\left(G_{N}\right)$ is partitioned to roots, leaves, stems and reproduction using empirical partitioning coefficients, which vary with stage of development (Kropff, 1993). Because leaf density increases with age, the new LAI (after total canopy LAI > 1.0) is calculated by adding the new leaf biomass to the existing leaf biomass and multiplying by specific leaf area (SLA = leaf area/leaf biomass). INTERCOM previously assumed a rectangular or parabolic distribution of leaf area over plant height (Kropff, 1993). Regnier \& Stoller (1989) showed the majority of A. theophrasti leaf area occurred above a soybean canopy. Their data and those of Tremmel \& Bazzaz (1995) suggest that vertical leaf area distribution is highly skewed with most leaf area near the top of the canopy. A new subroutine was written for INTERCOM to account for a skewed leaf area distribution. Relative LAI $\left(\mathrm{LAI}_{\mathrm{r}}=\mathrm{LAI}\right.$ within a layer divided by total LAI) as a function of relative plant height $\left(\mathrm{HT}_{\mathrm{r}}=\right.$ height of layer $\mathrm{h}\left(\mathrm{HT}_{\mathrm{h}}\right)$ divided by total height) is quantified using:

$$
\mathrm{LAI}_{\mathrm{r}}=1-\exp \left(-\left(\left(\frac{1-\mathrm{HT}_{\mathrm{r}}}{\mathrm{LD}_{\mathrm{a}}}\right)^{\mathrm{LD}_{\mathrm{b}}}\right)\right)
$$

where $1-\mathrm{LD}_{\mathrm{a}}$ defines the relative height at which maximum leaf area density $\left(\mathrm{m}^{2}\right.$ leaf $\mathrm{m}^{-3}$ canopy) occurs, and $\mathrm{LD}_{\mathrm{b}}$ defines the slope of the curve through the inflection point. Assuming that leaf area distribution is constant over developmental time, leaf area density ( $\mathrm{LD}=$ leaf area/canopy volume) at any relative height can then be calculated from actual LAI, height (HGHT), and the derivative of Equation (2) with respect to $\mathrm{HT}_{\mathrm{r}^{\prime}}$ which results in:

$$
\operatorname{LD}\left(\mathrm{HT}_{\mathrm{r}}\right)=\left(\frac{\left(\frac{1-\mathrm{HT}_{\mathrm{r}}}{\mathrm{LD}_{\mathrm{a}}}\right)^{\mathrm{LD}_{\mathrm{b}}} \mathrm{LD}_{\mathrm{b}} \exp \left(-\left(\frac{1-\mathrm{HT}_{\mathrm{r}}}{\mathrm{LD}_{\mathrm{a}}}\right)^{\mathrm{LD}_{\mathrm{b}}}\right)}{1-\mathrm{HTr}}\right) \frac{\mathrm{LAI}}{\mathrm{HGHT}}
$$

Estimates of $\mathrm{LD}_{\mathrm{a}}$ and $\mathrm{LD}_{\mathrm{b}}$ can be obtained by fitting relative LAI on relative HGHT using Equation (2). The time course of HGHT is defined logistically as a function of temperature sum (TS, Christensen, 1995):

$$
\mathrm{HGHT}=\frac{H_{\mathrm{m}}}{1+\exp \left(H_{\mathrm{a}}-H_{\mathrm{b}} \mathrm{TS}\right)}
$$

where $H_{\mathrm{m}}$ is maximum height, $H_{\mathrm{a}}$ and $H_{\mathrm{b}}$ are shape coefficients. The profile of diffuse intercepted PPFD within a canopy is calculated within INTERCOM using the LAI, canopy height, leaf area distribution and the extinction coefficient for diffuse radiation (Goudriaan, 1977; Kropff, 1993), all of which may vary among hybrids.

\section{Materials and methods}

\section{Field experiments}

Two experiments were conducted at the University of Nebraska Agricultural Re-

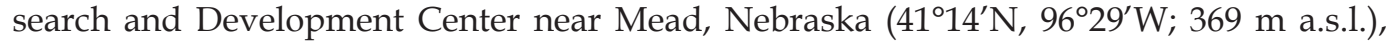
on Sharpsburg silty clay loam soils (fine, montmorillonitic mesic Typic Argiudolls) with 
$3.5 \%$ organic matter. A preliminary study, in which Pioneer 3379 maize (Pioneer Hi-Bred International, Johnston, IA, USA) and A. theophrasti were grown in monoculture, was conducted in 1994. An experimental unit was a six-row (0.76 m apart), 9.2-m-long plot. Sorghum (Sorghum bicolor L.) was grown in the field for 3 years before establishment of this study. The field was disked once in autumn and once for spring seedbed preparation. Ammonium nitrate fertilizer (treatments ranging from 0 to $175 \mathrm{~kg} \mathrm{~N} \mathrm{ha}^{-1}$ ) was applied pre-planting with a 4.6-m drop spreader on May 3, 1994. Maize and A. theophrasti were seeded with a John Deere max-emerge planter (Deere and Co, Moline, IL, USA) and a push planter respectively. Further experimental details are shown in Table 1. Except for the $\mathrm{CO}_{2}$ assimilation measurements, only data obtained within the greatest $\mathrm{N}$ treatment $\left(175 \mathrm{~kg} \mathrm{~N} \mathrm{ha}^{-1}\right)$ were used for these analyses.

The second experiment, conducted on adjacent fields in 1995 and 1996, was designed as a randomized complete block with four replicates. Within a block, two old hybrids (336 and 344, released in 1940 and 1945, respectively, by Pioneer Hi-Bred International, Johnston, IA, USA), two modern hybrids (3379 and 3394, Pioneer Hi-Bred International), and A. theophrasti were grown in monoculture. An experimental unit was a six-row $(0.76 \mathrm{~m}$ apart), 14-m-long plot. Soyabean was grown during the year before establishment. Fields were disked and field cultivated to prepare the seedbed in spring. Ammonium nitrate was broadcast before planting in 1995, and anhydrous ammonia was applied in autumn (1995) for the 1996 experiment. Maize was seeded with a Case 900 Cycloair planter (Case Racine, WI, USA). Abutilon theophrasti was seeded using a push planter. Grass weeds were controlled with a pre-emergence broadcast application of alachlor (Lasso, $480 \mathrm{~g}$ a.i L $\mathrm{L}^{-1}$, Monsanto, St. Louis, MO, USA) at $0.42 \mathrm{~kg}$ a.i. ha ${ }^{-1}$ in each experiment (1994-96). Other weeds were controlled with cultivation and by hand as needed. Plots were sprinkler irrigated weekly beginning on July 11 in both 1995 and 1996.

Two plants were harvested destructively in each plot each week for 4 weeks after emergence, then at 2-3 week intervals until maturity. Plant height was measured before stem cutting at the soil surface at each harvest. Before the eight-leaf stage, maize height was measured to the extended tip of the tallest leaf. After a distinct bend was observed in maize

Table I. Date of field operations, mean maize and Abutilon theophrasti density and nitrogen application rate within each year. Dates are reported as day of year (terms in parentheses in month/day format).

\begin{tabular}{lrrr}
\hline & 1994 & 1995 & 1996 \\
\hline Seeding date of maize & $124(5 / 4)$ & $139(5 / 19)$ & $128(5 / 7)$ \\
Seeding date of A. theophrasti & $125(5 / 5)$ & $142(5 / 22)$ & $135(5 / 14)$ \\
Date of 50\% maize emergence & $133(5 / 13)$ & $148(5 / 29)$ & $140(5 / 19)$ \\
Date of 50\% A. theophrasti emergence & $133(5 / 13)$ & $148(5 / 29)$ & $140(5 / 19)$ \\
Mean hybrid density (plants $\mathrm{m}^{-2}$ ) & & & \\
$\quad 336$ & - & 5.51 & 4.15 \\
344 & - & 6.33 & 4.06 \\
3379 & 4.93 & 5.35 & 4.24 \\
3394 & - & 5.67 & 4.87 \\
Mean A. theophrasti density (plants $\left.\mathrm{m}^{-2}\right)$ & 164.78 & 24.91 & $170(6 / 18)$ \\
Date of cultivation & - & $173(6 / 22)$ & $171(6 / 19)$ \\
Date of A. theophrasti thinning & $220(8 / 8)$ & $186(7 / 5)$ & $212(7 / 30)$ \\
Date of density counts & $194(7 / 13)$ & $207(7 / 26)$ & $205(7 / 23)$ \\
Date of maize anthesis & $258(9 / 15)$ & $261(9 / 28)$ & $263(9 / 19)$ \\
Maize physiological maturity & 175 & $1 / 10$ & 120 \\
Nitrogen fertilizer rate $\left(\mathrm{kg} \mathrm{ha}^{-1}\right)$ & & & \\
\hline
\end{tabular}


leaves, the height was measured at the tallest point on the undisturbed plant. After tassel emergence, the height was measured to the top of the tassel. Abutilon theophrasti height was measured at the tallest point on the plant throughout the season. Harvested plants were separated by organ group. Green leaves were separated by cutting the lamina at the ligule for maize or at the point of attachment of the petiole to the lamina for A. theophrasti. Newly emerged maize leaves were cut just above the youngest visible collar. Reproductive organs (including husk, shank, cob and tassel in maize, and the complete capsule in A. theophrasti) were separated at their nodes. All remaining material was considered to be stem. Leaf area was measured with an area meter (LI-3100, LiCor, Lincoln, NE, USA), the youngest maize leaves were left furled for these measurements. The weight of each organ group was obtained after drying at $60^{\circ} \mathrm{C}$ until constant weight was reached. Dry leaf samples from the 1994 experiment were ground and submitted to the University of Nebraska Plant and Soil Testing Laboratory for analysis of leaf nitrogen content. Results from destructive harvests were used to obtain estimates of $\ln \left(\mathrm{LAI}_{\mathrm{o}}\right)$, RGRL, average canopy leaf nitrogen content, shoot partitioning coefficients, SLA and canopy height.

To calculate root and shoot partitioning coefficients for early season growth, estimates of root:shoot biomass ratio were obtained at four sampling times in 1995. Roots of 10 randomly selected maize hybrid 3379 and A. theophrasti plants were excavated to a depth of $35 \mathrm{~cm}$ with a shovel and gently washed in a bucket of water. Shoots and roots were then separated and dried (at $60^{\circ} \mathrm{C}$ ) to constant weight.

To obtain a relationship between single leaf $C_{\mathrm{A}}$ and PPFD, $C_{\mathrm{A}}$ was measured on individual leaves of both maize and $A$. theophrasti using a portable photosynthesis system (LI6200, LiCor). Measurements were taken on July 20 and 21, 1994 and August 8-10, 1995. To ensure that $C_{A}$ was obtained for a full range of PPFD values and represented whole-canopy response to PPFD, five leaves were selected (ear leaf, and two and four leaves above and below the ear leaf) for measurement in each plot. A 1.0-L chamber (with restrictors to keep the leaf area within the chamber constant at $11 \mathrm{~cm}^{2}$ ) was clamped across the entire width of maize leaves $\approx 20 \mathrm{~cm}$ from the leaf tip, where the midrib was not large enough to cause chamber leakage. For $A$. theophrasti measurements, the same chamber was clamped across a portion of or the entire leaf (depending on leaf size). All measurements were taken between $10.00 \mathrm{~h}$ and $14.00 \mathrm{~h}$. Mean air temperatures at the times of measurement were $29.7^{\circ} \mathrm{C}\left( \pm 0.8^{\circ} \mathrm{C}\right)$ in 1994 and $34.5^{\circ} \mathrm{C}\left( \pm 0.8^{\circ} \mathrm{C}\right)$ in 1995 .

Single-leaf $\mathrm{CO}_{2}$ assimilation measurements were made under full-sun conditions on August 15, 1994, to obtain a relationship between $A_{\mathrm{m}}$ and leaf nitrogen content $\left(N_{\mathrm{L}}\right)$ of field grown maize and $A$. theophrasti plants. After measurement, each leaf was harvested, the leaf area measured, dried, weighed and then analyzed for $N_{\mathrm{L}}$.

To determine vertical leaf area distribution parameters and the extinction coefficient, one harvest was taken shortly after anthesis in each year, plants were separated post harvest at $30-\mathrm{cm}$ intervals from the top of the canopy to the ground. Plants were then further separated into leaves, stems and reproductive organs at each height interval. Attenuation of diffuse PPFD was measured under uniform cloudy conditions using a line quantum sensor (LI191-SA, LiCor) within 2 days of this harvest in 1994 and 1996.

\section{Data analysis}

Where functional relationships were used, linear or non-linear least-squares regression (Draper \& Smith, 1998) was used to obtain coefficient estimates. Differences among hybrids were tested using estimates of regression coefficients obtained for each experimen- 
tal unit. Linear contrasts were used to compare estimates between old (336 and 344) and modern (3379 and 3394) hybrids, between the two old hybrids and between the two modern hybrids using the general linear models procedure in SAS (SAS, 1986). In cases where it was not appropriate to fit a function to data, linear contrasts were used to compare mean estimates at each sampling time.

\section{Results and discussion}

\section{Phenology}

The two old maize hybrids reached 50\% anthesis about 1 day earlier and showed greater variability among individual plants in the date of anthesis than the modern hybrids in both years (data not shown). The two old hybrids also reached physiological maturity 3-5 days earlier than the modern hybrids, but this had little impact on the number of day degrees accumulated between emergence and maturity. Duvick (1992) provided a description of many phenotypic characteristics and yield of the two old hybrids relative to a number of Pioneer hybrids, both old and new.

\section{Early leaf area growth rate}

Abutilon theophrasti RGRL was greater than that for all maize hybrids in 1995, but less than all hybrids in 1994 and 1996. RGRL and $\ln \left(\mathrm{LAI}_{\mathrm{o}}\right)$ did not differ among hybrids in 1996, but 3379 maize had smaller intercept and greater RGRL than 3394 maize in 1995 (Table 2).

Maize RGRL differed among years (Figure 1). The estimate of RGRL was consistently greater and the intercept $\left[\ln \left(\mathrm{LAI}_{\mathrm{o}}\right)\right.$, where $\mathrm{LAI}_{\mathrm{o}}$ is apparent LAI at emergence] lower in 1996 than in 1995 or 1994 (Table 2, Figure 1). Maize establishment was inhibited in 1996 by exceptionally high soil moisture immediately after planting followed by rapid crusting at the soil surface. Consequently, maize population density was about 10,000 plants ha $^{-1}$ less in 1996 than in 1995 (Table 1). This variation in population between years contributed to differences in apparent LAI at emergence. However, estimated intercepts of a regression of $\ln \left(\right.$ leaf area plant ${ }^{-1}$ ) on temperature sum were also different between years (data not shown), indicating that differences in RGRL and $\ln \left(\mathrm{LAI}_{\mathrm{o}}\right)$ among hybrids result at least in part from variation in environmental conditions between years. Despite lower mean daily temperatures during the first 3 weeks after emergence in 1996 (data not shown), RGRL was greater in that year. This result suggests that air temperature may not be the best predictor of early leaf growth. Given the potential importance of RGRL to simulated crop performance in mixture (Lindquist \& Kropff, 1996), further research is needed to improve the method of quantifying early leaf area growth to account for among-year variation in environmental factors.

\section{$\mathrm{CO}_{2}$ assimilation rate}

Maize and $A$. theophrasti $A_{\mathrm{m}}$ (Table 3) were similar to those reported by others (Regnier et al., 1988 ; Louwerse et al., 1990 ; Dwyer et al., 1992a). Abutilon theophrasti light use efficiency $(\varepsilon)$ estimates were within the range reported for other $C_{3}$ species, but estimates for maize were higher than those reported for $C_{4}$ species (Ehleringer \& Pearcy, 1983). The relationship between $C_{\mathrm{A}}$ and absorbed PPFD did not vary among hybrids in 1995, but did vary among years. Estimates of maize $A_{\mathrm{m}}$ were similar between years, but the estimate of $\varepsilon$ was lower in 1994 than in 1995. The reason for this is not clear. Estimates of both $\varepsilon$ and $A_{\mathrm{m}}$ obtained for $A$. theophrasti in August 1995 were less than from mid-July 1994 (Table 3). 
Table 2. Mean estimated regression coefficients for eight morphological parameters of maize and Abutilon theophrasti. Linear contrasts comparing old vs. modern hybrids, two old hybrids and two modern hybrids and the standard error of the mean are reported for each year.

\begin{tabular}{|c|c|c|c|c|c|c|c|c|c|}
\hline & Species & $\ln \left(L A I_{0}\right)$ & RGRL & $\mathrm{LD}_{\mathrm{a}}$ & $\mathrm{LD}_{\mathrm{b}}$ & $H_{m}$ & $H_{a}$ & $H_{b}$ & $k_{\mathrm{df}}$ \\
\hline \multirow{2}{*}{1994} & A. theophrasti & -7.83 & 0.0174 & 0.29 & 1.78 & 730 & 5.28 & 0.0062 & $0.5 \mathrm{I}$ \\
\hline & Maize hybrid 3379 & -6.55 & 0.0188 & 0.59 & 2.67 & 267 & 3.27 & 0.0074 & 0.61 \\
\hline \multirow[t]{5}{*}{1995} & A. theophrasti & -5.91 & 0.0148 & 0.20 & 1.21 & 243 & 4.62 & 0.0067 & - \\
\hline & Maize hybrid 336 & -4.40 & 0.0118 & 0.50 & 2.35 & 312 & 2.73 & 0.0050 & - \\
\hline & Maize hybrid 344 & -4.29 & 0.0116 & 0.51 & 2.27 & 291 & 2.76 & 0.0054 & - \\
\hline & Maize hybrid 3379 & -4.87 & 0.0128 & 0.57 & 2.57 & 286 & 2.84 & 0.0057 & - \\
\hline & Maize hybrid 3394 & -4.12 & 0.0108 & 0.54 & 2.63 & 274 & 2.60 & 0.0054 & - \\
\hline Old vs. modern & & NS & NS & $* *$ & $*$ & $*$ & NS & NS & - \\
\hline 336 vs. 344 & & NS & NS & NS & NS & NS & NS & NS & - \\
\hline 3379 vs. 3394 & & *** & $* * *$ & NS & NS & NS & * & NS & - \\
\hline Standard error & & 0.16 & 0.0005 & 0.01 & 0.11 & 8 & 0.06 & 0.0002 & - \\
\hline \multirow[t]{5}{*}{1996} & A. theophrasti & -7.18 & 0.0221 & 0.21 & 1.26 & 233 & 4.52 & 0.0070 & 0.87 \\
\hline & Maize hybrid 336 & -6.06 & 0.0236 & 0.46 & 2.28 & 284 & 3.25 & 0.0068 & 1.04 \\
\hline & Maize hybrid 344 & -5.96 & 0.0229 & 0.52 & 2.37 & 284 & 3.33 & 0.0070 & 0.76 \\
\hline & Maize hybrid 3379 & -6.17 & 0.0238 & 0.51 & 2.40 & 275 & 3.21 & 0.0073 & 0.85 \\
\hline & Maize hybrid 3394 & -5.94 & 0.0242 & 0.53 & 2.24 & 276 & 3.06 & 0.0070 & 0.65 \\
\hline Old vs. Modern & & NS & NS & NS & NS & NS & NS & NS & NS \\
\hline 336 vs. 344 & & NS & NS & * & NS & NS & NS & NS & NS \\
\hline 3379 vs. 3394 & & NS & NS & NS & NS & NS & NS & NS & NS \\
\hline Standard error & & 0.21 & 0.0014 & 0.02 & 0.08 & 5 & 0.08 & 0.0002 & 0.14 \\
\hline
\end{tabular}

NS, not significant; $* P<0.05 ; * * P<0.01$ I *** $P<0.00$ I

$\ln \left(\mathrm{LAI}_{\circ}\right)$ and $R G R L$ are the intercept and slope of a regression of $\ln (\mathrm{LAl})$ on temperature sum respectively. $\ln \left(\mathrm{LAI}_{\circ}\right)$ is the apparent leaf area index at emergence and RGRL is the early leaf area growth rate. $L_{a}$ and $L D_{b}$ determined by fitting relative LAI on relative HGHT using Equation (2). $L D_{a}$ is the relative height of maximum leaf area density and $L_{b}$ is the slope of the line through the inflection point. $H_{m}, H_{a}$, and $H_{b}$ were determined by fitting HGHT on temperature sum using Equation (4). $H_{\mathrm{m}}$ is maximum $\mathrm{HGHT}, H_{\mathrm{a}}$ and $H_{\mathrm{b}}$ are shape coefficients. $k_{\mathrm{df}}$ is the extinction coefficient for diffuse radiation, obtained by fitting the fraction of incident radiation (measured PPFD within the canopy divided by measured PPFD above the canopy) on cumulative LAI (from the top of the canopy to the soil surface) using a negative exponential equation.

This difference may be the result of differences in temperature between sampling dates, because a negative correlation between quantum efficiency $(\varepsilon)$ and temperature has been shown (Ehleringer \& Pearcy, 1983). Alternatively, these differences may reflect leaf age at time of sampling, as several authors have shown that the assimilation response varies with leaf age (e.g. Louwerse et al., 1990 ; Dwyer et al., 1995).

As may be expected, maize $A_{\mathrm{m}}$ was greater than that for $A$. theophrasti across all observed $N_{\mathrm{L}}$ values (Figure 2). However, because ribulose 1,5-bisphosphate carboxylase (RUBISCO) and phosphoenolpyruvate carboxylase account for a smaller fraction of the total soluble proteins in $\mathrm{C}_{4}$ plants than does RUBISCO in $\mathrm{C}_{3}$ species, it may be expected that the $A_{\mathrm{m}}-N_{\mathrm{L}}$ relationship is not as strong for $\mathrm{C}_{4}$ species. Indeed, greater variability was observed in the $A_{\mathrm{m}}-N_{\mathrm{L}}$ relationship for maize than for $A$. theophrasti (Figure 2). The curve presented for maize in Figure 2 is similar to that reported by Sinclair \& Horie (1989), but with a lower $A_{\max }$. The $A_{\mathrm{m}}-N_{\mathrm{L}}$ relationship was not quantified in 1995 or 1996, so a comparison among hybrids is not available.

Abutilon theophrasti $A_{\mathrm{m}}$ was lower across the entire range of observed $N_{\mathrm{L}}$ values (Figure 2). Therefore, its biomass accumulation is expected to be lower than that of maize across all nitrogen supply situations. Moreover, the range of leaf $\mathrm{N}$ measured in field 


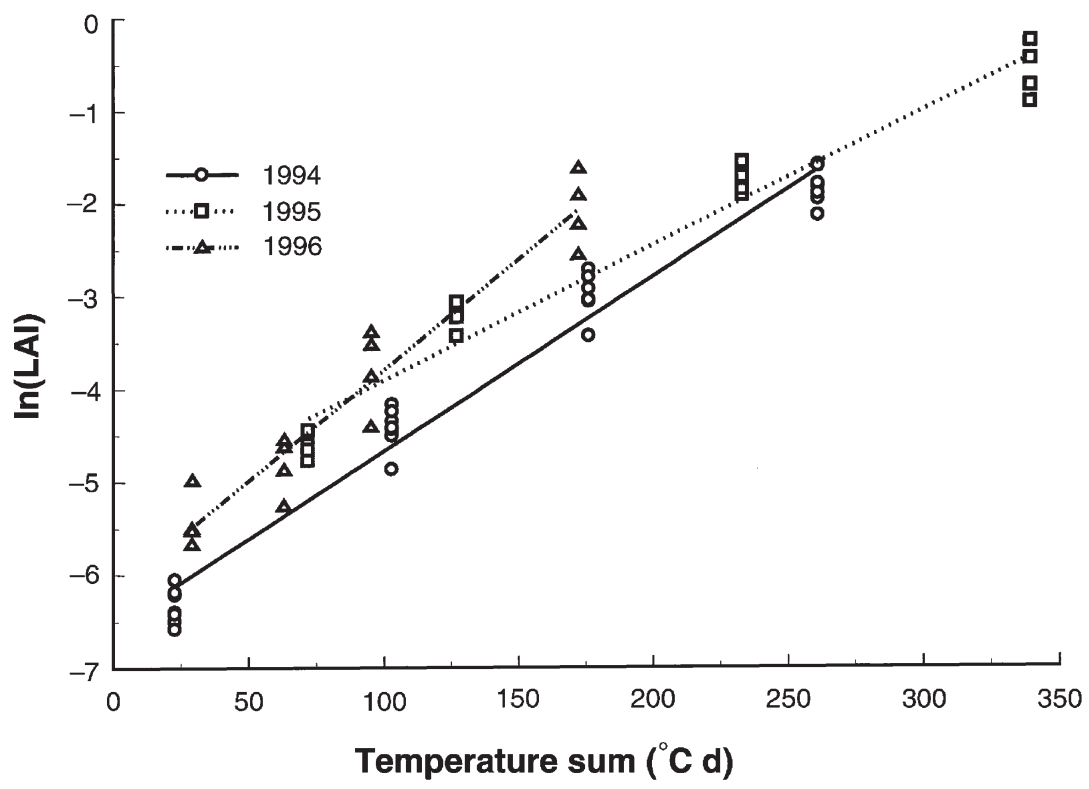

Figure 1. Exponential relationship between leaf area index (LAI) and temperature sum during early season growth for Pioneer 3379 maize in three growing seasons.

Table 3. Estimates of $\varepsilon\left[\mu \mathrm{mol} \mathrm{CO} \mathrm{CO}^{-2} \mathrm{~s}^{-1}\left(\mu \mathrm{mol} \mathrm{m} \mathrm{m}^{-2} \mathrm{~s}^{-1}\right)^{-1}\right]$ and $A_{\mathrm{m}}\left(\mu \mathrm{mol} \mathrm{CO} \mathrm{CO}^{-2} \mathrm{~s}^{-1}\right.$ for regression of $C_{A}$ on PPFD for maize and Abutilon theophrasti in 1994 (July 20 and 2l) and 1995 (August 8-10). Estimates did not vary among hybrids in 1995.

\begin{tabular}{rlll}
\hline Species & Year & $\varepsilon$ & $A_{\mathrm{m}}$ \\
\hline Maize (3379) & 1994 & $0.074(0.007)$ & $42.48(2.13)$ \\
(all hybrids) & 1995 & $0.107(0.008)$ & $44.23(1.56)$ \\
A. theophrasti & 1994 & $0.054(0.003)$ & $37.47(1.82)$ \\
& 1995 & $0.043(0.003)$ & $28.47(1.37)$ \\
\hline
\end{tabular}

grown maize (8-24 $\mathrm{kg} \mathrm{N}$ ha $^{-1}$ leaf) was only half that observed for A. theophrasti (4$36 \mathrm{~kg} \mathrm{~N} \mathrm{ha}^{-1}$ leaf, Figure 2), suggesting that maize is more efficient at nitrogen acquisition and utilization than $A$. theophrasti.

Because nitrogen uptake and utilization are not currently simulated within INTER$\mathrm{COM}$, leaf nitrogen content is required input. Results indicated that percentage leaf nitrogen $([\mathrm{N}])$ was less variable as a function of temperature sum than leaf $\mathrm{N}$ per unit leaf area (data not shown). Abutilon theophrasti [N] showed a linear decline with temperature sum (Figure 3), whereas the decline in maize $[\mathrm{N}]$ was curvilinear according to: $[\mathrm{N}]=c \exp \left(-d_{\mathrm{n}}\right.$ TS), where $c$ is $[\mathrm{N}]$ at emergence (5.06 \pm 0.10 for maize, and $5.68 \pm 0.10$ for $A$. theophrasti) and $d_{\mathrm{n}}$ is the slope $(0.00073 \pm 0.00003$ for maize and $0.0014 \pm 0.0002$ for $A$. theophrasti). Leaf $\mathrm{N}$ per unit leaf area $\left(N_{\mathrm{L}}\right)$ is calculated as the product of $[\mathrm{N}]$ and the inverse of specific leaf area within INTERCOM.

\section{Biomass partitioning}

Abutilon theophrasti partitioned less new biomass to roots $\left(p_{\mathrm{rt}}\right)$ than shoots $\left(p_{\mathrm{sht}}\right)$ than maize during early development (Table 4 ). Observed values of $p_{\text {rt }}$ and $p_{\text {sht }}$ for $A$. theo- 


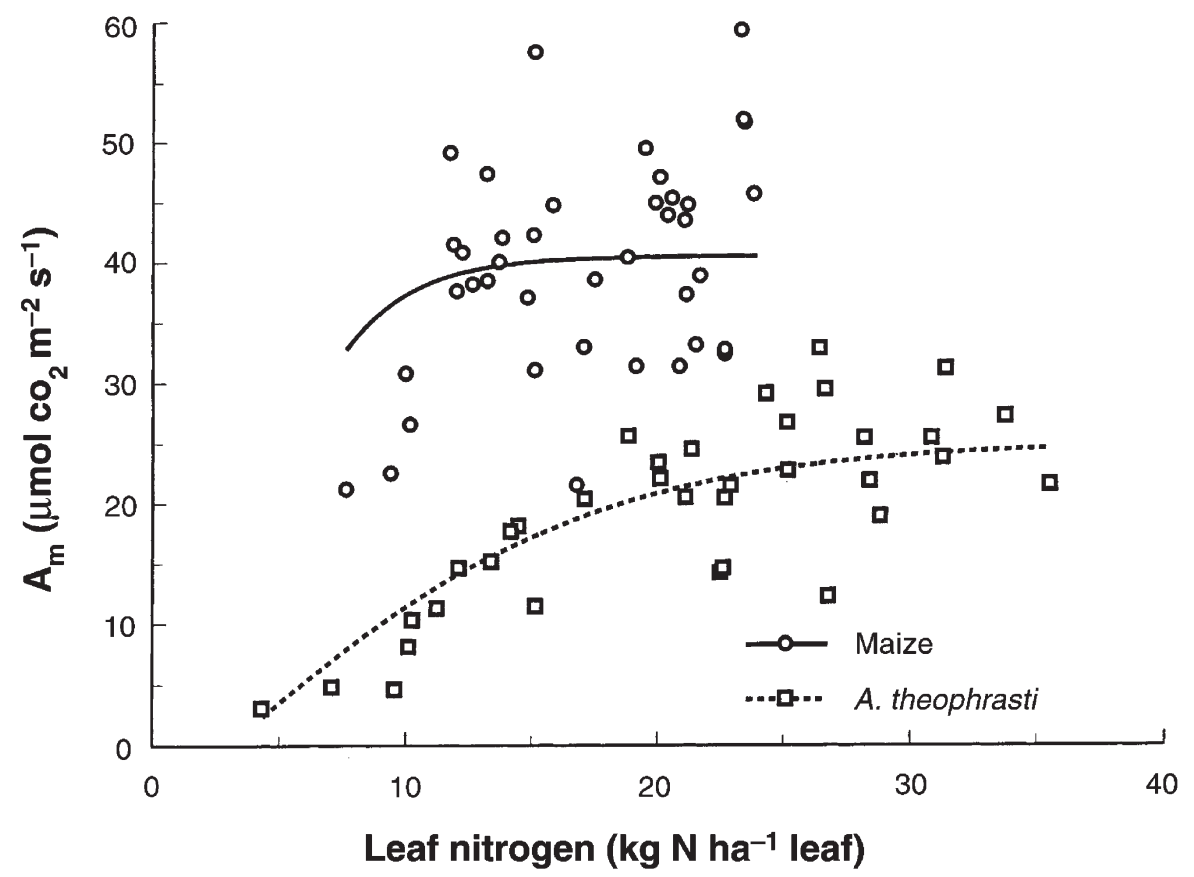

Figure 2. Full-sun $\mathrm{CO}_{2}$ assimilation rate $\left(A_{\mathrm{m}}\right)$ of maize (Pioneer 3379) and Abutilon theophrasti as a function of leaf nitrogen content on August 15, 1994. $\mathrm{A}_{\max \text { maize }}=40.47 \pm 1.31 ; A_{\max }$ A. theophrasti $=$ $24.63 \pm 0.93 . r$

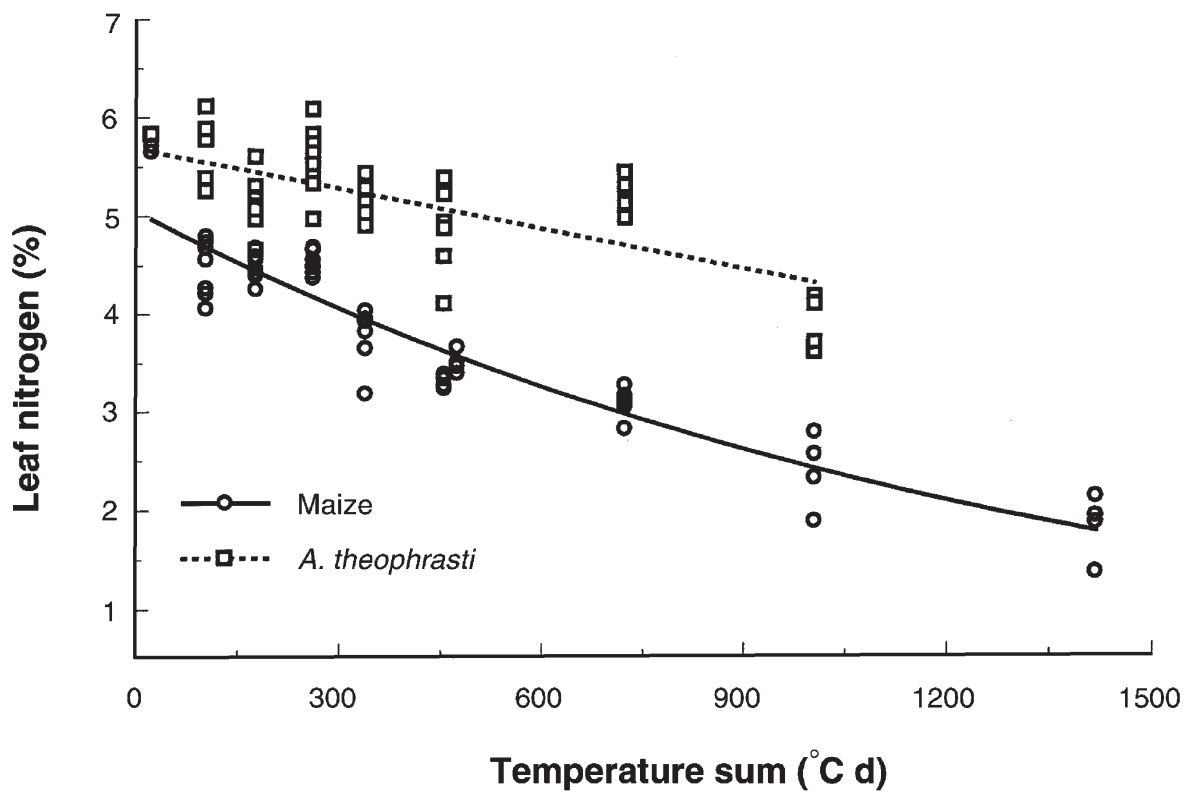

Figure 3. Percentage of leaf nitrogen content $\left[N_{\mathrm{L}}(\%)=\mathrm{g} \mathrm{N} \mathrm{g}^{-1}\right.$ leaf $]$ of 3379 maize and A. theophrasti as a function of day degrees accumulated from emergence (temperature sum) in 1994. 
Table 4. Partitioning coefficients ( \pm standard error) for shoot $\left(p_{\text {sht }}\right)$ and root $\left(p_{\mathrm{rt}}\right)$ during early development in 1994.

\begin{tabular}{llll}
\hline Species & DVS & $p_{\text {sht }}$ & $p_{\text {rt }}$ \\
\hline A. theophrasti & 0.051 & $0.69(0.02)$ & $0.31(0.02)$ \\
& 0.140 & $0.77(0.04)$ & $0.23(0.04)$ \\
Maize - 3379 & 0.315 & $0.93(0.01)$ & $0.07(0.01)$ \\
& 0.048 & $0.56(0.02)$ & $0.44(0.02)$ \\
& 0.134 & $0.54(0.04)$ & $0.46(0.04)$ \\
& 0.301 & $0.71(0.01)$ & $0.29(0.01)$ \\
\hline
\end{tabular}

Development stage (DVS, $0=$ emergence, $1.0=$ maize anthesis or $A$. theophrasti flower initiation, $2.0=$ maize physiological maturity or A. theophrasti complete leaf senescence).

phrasti were lower than those reported by Coleman \& Bazzaz (1992), whereas values for maize were similar to those presented by Kropff \& Lotz (1993). In 1995 the old hybrid 344, compared with the other three hybrids, partitioned a greater proportion of new biomass to leaves at a development stage (DVS) of 0.98 (c. anthesis, Figure 4). The two old hybrids (336 and 344) partitioned more new biomass to stems relative to reproductive organs than did newer hybrids at DVS = 1.27 in 1995 (Figure 4). If this trend were consistent through reproductive development and across years, it might explain the substantial differences in total reproductive yield among hybrids. However, partitioning coefficients were similar among hybrids in 1996.

The fraction of new biomass partitioned to A. theophrasti leaves was variable in 1994 compared with 1995 or 1996, but trends were similar (Figure 4). In 1996, a strong reduction in partitioning to leaves occurred at DVS $=0.12$. Plasticity of biomass partitioning is apparently much greater in $A$. theophrasti than in maize.

\section{Specific leaf area}

McCullough et al. (1994) found no differences in SLA during the four- to eight-leaf stages of development of an old and a new maize hybrid. However, the new hybrid had greater SLA at the eight- to 12-leaf stages. Maize SLA estimates shown in Figure 5 are within the range reported by McCullough et al. (1994), and differences in SLA occurred among hybrids during the eight- to 12-leaf stage (DVS = 0.85 and 0.65 in 1995 and 1996 respectively). However, the two old hybrids had greater SLA than the newer hybrids at this growth stage in both years. Differences in SLA among hybrids during early growth (DVS $=0.24$ ) in 1996 may be due, in part, to difficulties in establishing the crop in this year.

Mean canopy SLA for A. theophrasti (Figure 5) was similar to values reported by Bazzaz et al. (1989) and Regnier et al. (1988). The lower A. theophrasti SLA estimates observed in 1994 than in other years may be the result of lower stand densities of A. theophrasti observed in that year (Table 1). SLA may be underestimated during early growth because $A$. theophrasti cotyledons were not separated from stem for leaf area or biomass measurements from emergence until the first fully expanded leaf.

\section{Leaf area distribution}

Abutilon theophrasti leaf area was distributed higher in the canopy in 1995 and 1996 than in 1994 (Table 2), perhaps as a result of the greater stand densities in these two years. Leaf area was distributed higher in the canopy of the two old maize hybrids in 1995, but 


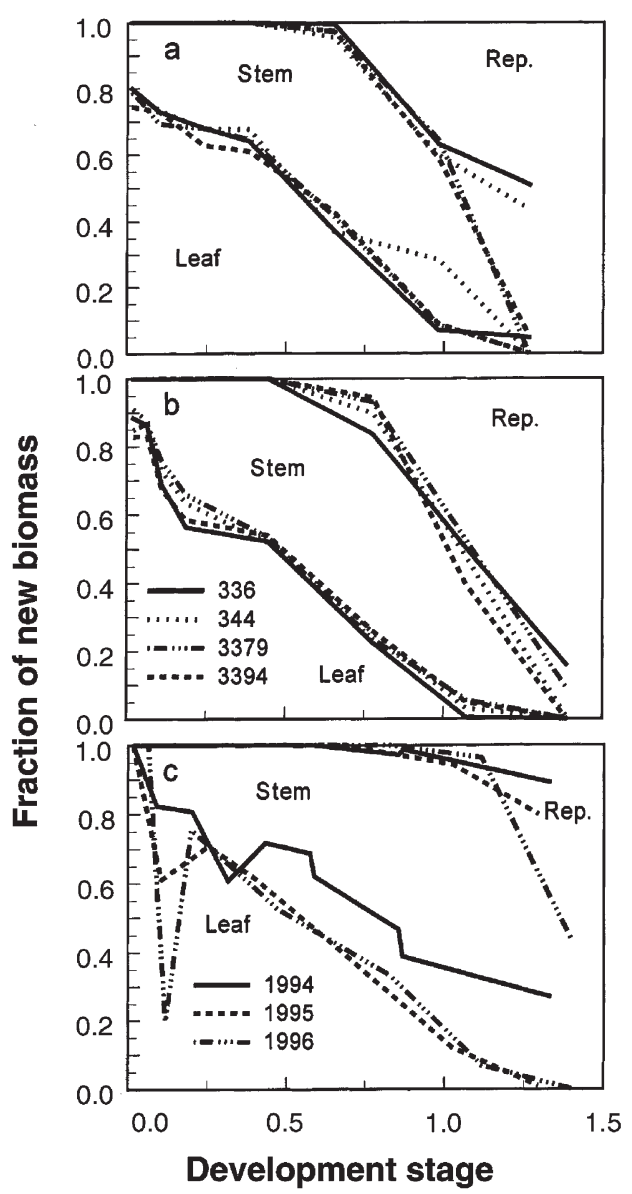

Figure 4. Mean fraction of new shoot biomass partitioned to leaves, stems and reproductive organs (rep.) as a function of development stage for maize in 1995 (a) and 1996 (b) and for Abutilon theophrasti (c).

only of hybrid 336 in 1996. Dwyer et al. (1992b) showed similar differences in leaf area distribution among maize genotypes. Under conditions where maize is competing for light, hybrids with leaf area distributed higher in the canopy may intercept greater PPFD. The relationships between leaf area density and plant height (Figure 6) suggest that the two old hybrids would intercept a greater amount of PPFD above the A. theophrasti canopy than the two new maize hybrids, assuming that height and LAI are the same in mixture as in monoculture.

\section{Height growth}

The rate of $A$. theophrasti height growth was least in 1994 compared with 1995 or 1996 and the observed maximum height was greatest in 1995 (Table 2, statistics not shown). Maximum height and height growth rate of $A$. theophrasti were always lower than that of maize. Maximum estimated height $\left(H_{\mathrm{m}}\right)$ was greater for the two old maize hybrids in both 1995 and 1996 (Table 2). 


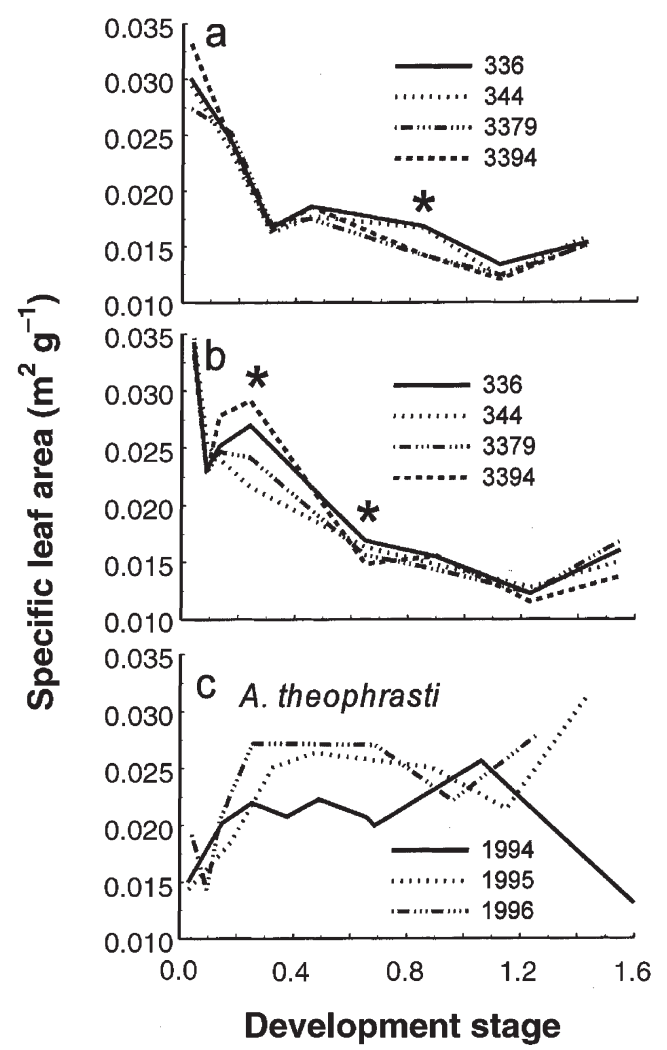

Figure 5. Mean specific leaf area (SLA) as a function of development stage for maize in 1995 (a) and 1996 (b) and for Abutilon theophrasti (c). An asterisk indicates that SLA varies significantly $(P<0.05)$ among hybrids at that sampling date.

\section{Extinction coefficient for diffuse radiation}

Estimates of $k_{\mathrm{df}}$ did not differ among maize hybrids in 1996 (Table 2). The 1994 estimates of $k_{\mathrm{df}}$ are within the range of those reported by Flenet et al. (1996), but some of the 1996 values were greater. Greater $k_{\mathrm{df}}$ implies a greater efficiency of PPFD interception per unit LAI. The higher values of $k_{\mathrm{df}}$ observed in 1996 may reflect phenotypic plasticity in light interception efficiency resulting from a smaller canopy LAI.

\section{Conclusions}

Observed variation in morphological traits among the four maize hybrids may lead to differences in light interception and competitive ability. Early leaf area growth rate varied little among hybrids within a year. However, variation among years was substantial (Figure 1) and A. theophrasti RGRL exceeded that of all maize hybrids in one out of three years, suggesting that environmental factors may substantially influence early season competition for light. Greater estimates of light use efficiency $(\varepsilon)$ and light-saturated $\mathrm{CO}_{2}$ assimilation $\left(A_{\mathrm{m}^{\prime}}\right.$ Table 3$)$ suggest that maize is more efficient at producing biomass at all PPFD levels than $A$. theophrasti. However, greater efficiency in the conversion of light energy to biomass does not necessarily indicate greater competitiveness because the efficiency of radia- 


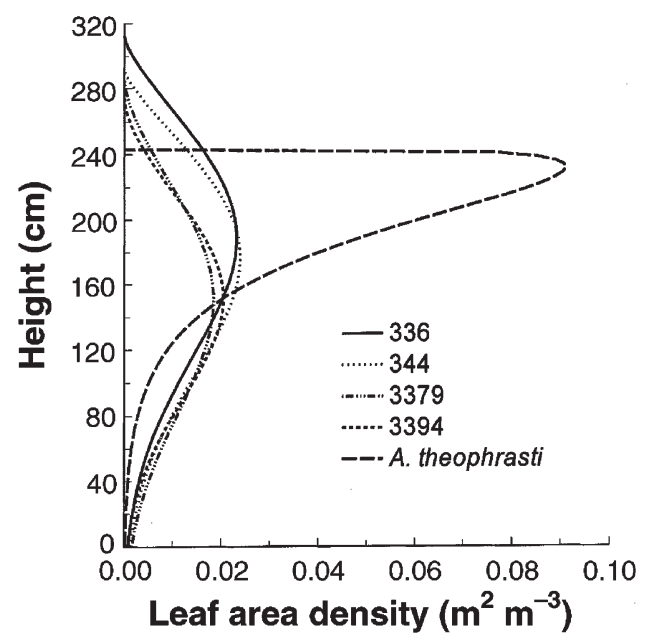

Figure 6. Relative leaf area density over plant height for four monoculture-grown maize hybrids and Abutilon theophrasti on August 3, 1995.

tion capture must also be accounted for. Greater partitioning of new growth to leaves may have resulted in greater LAI of the two old maize hybrids in at least one year. Greater LAI would subsequently lead to greater light interception during the reproductive phase of development. Leaves of the old hybrids had greater SLA relative to new hybrids before anthesis (Figure 5). Assuming equal biomass in the leaves, a greater SLA also results in greater LAI. Lower values of the $\mathrm{LD}_{\mathrm{a}}$ coefficient in Equation (3) indicate that leaf area was distributed higher on the plants of the old hybrids, particularly 336 (Figure 6, Table 2). A preliminary analysis of INTERCOM showed that a $10 \%$ decrease in $\mathrm{LD}_{\mathrm{a}}$ may increase maize yield by $1 \%$ and reduce yield loss caused by $A$. theophrasti by $>5 \%$ (Lindquist \& Mortensen, 1997). Combining greater LAI, high leaf area distribution, and greater maximum height (Table 2) of the two old hybrids, multispecies light interception models predict greater light interception high in the canopy and an increase in crop competitiveness for light (Lindquist \& Mortensen, 1997). Our results suggest that the two old hybrids will produce greater relative yields in the presence of $A$. theophrasti than the newer hybrids.

Empirical comparison of maize and $A$. theophrasti canopy morphology revealed that some characteristics may vary sufficiently among genotypes to improve maize competitiveness for light. Detailed understanding of the effects of these traits and their variation on crop:weed competition may be useful for identifying crop traits that enhance performance in both monoculture and in mixtures. Incorporation of these results into a dynamic simulation model such as INTERCOM will be useful for conducting a quantitative analysis of the effects of each trait and its potential variability on crop:weed competitive relationships.

\section{Acknowledgments}

Contribution of the University of Nebraska Agricultural Research Division Journal Series number 12018. This research was supported in part by USDA/CSRS National Research Initiative Competitive Grant Number 95-37315-2049. We thank W. Wilhelm and R. Caldwell for helpful comments on an early draft, and D. Duvick for providing seed of Pioneer brands 336 and 344. 


\section{References}

Bazzaz FA, Garbutt K, Reekie EG, Williams WE (1989) Using growth analysis to interpret competition between $\mathrm{a}_{3}$ and $\mathrm{a} \mathrm{C}_{4}$ annual under ambient and elevated $\mathrm{CO}_{2}$. Oecologia 79, 223-235.

Bridges DC (1992) Crop Losses Due To Weeds in the United States - 1992. Weed Science Society of America, Lawrence, KS.

Caldwell RM, Pachepsky YA, Timlin DJ (1996) Current research status on growth modeling in intercropping. In: Dynamics of Roots and Nitrogen in Cropping Systems of the Semi-Arid Tropics (eds. O Ito, C Johansen, JJ Adu-Gyamfi, K Katayama, JVDK Kumar Rao, \& TJ Rego), 617-635. Japan International Centre for Agricultural Sciences, Ohwashi, Tsukuba, Ibaraki 305, Japan.

Christensen S (1995) Weed suppression ability of spring barley varieties. Weed Research 35, 241-247.

Coleman JS, \& Bazzaz FA (1992) Effects of $\mathrm{CO}_{2}$ and temperature on growth and resource use of cooccurring $\mathrm{C}_{3}$ and $\mathrm{C}_{4}$ annuals. Ecology $73,1244-1259$.

Cousens RD (1996) Comparative growth of wheat, barley, and annual ryegrass (Lolium rigidum) in monoculture and mixture. Australian Journal of Agricultural Research 47, 449-464.

Draper NR, \& Smith H (1998) Applied Regression Analysis. John Wiley \& Sons, New York.

Duvick DN (1992) Genetic contributions to advances in yield of U.S. maize. Maydica 37, 69-79.

Dwyer LM, Stewart DW, \& Tollenaar M (1992a) Analysis of corn leaf photosynthesis under drought stress. Canadian Journal of Plant Science 72, 477-481.

Dwyer LM, Stewart DW, Hamilton RI, \& Houwing L (1992b) Ear position and vertical distribution of leaf area in corn. Agronomy Journal 84, 430-438.

Dwyer LM, Anderson AM, Stewart DW, \& Tollenaar M (1995) Changes in maize hybrid photosynthetic response to leaf nitrogen, from pre-anthesis to grain fill. Agronomy Journal 87, 1221-1225.

Ehleringer J, \& Pearcy RW (1983) Variation in quantum yield for $\mathrm{CO}_{2}$ uptake among $\mathrm{C}_{3}$ and $\mathrm{C}_{4}$ plants. Plant Physiology 73, 555-559.

Flenet R, Kiniry JR, Board JE, Westgate ME, \& Reicosky DC (1996) Row spacing effects on light extinction coefficients of corn, sorghum, soybean, and sunflower. Agronomy Journal 88, 185-190.

Goudriaan J (1977) Crop Micrometeorology: a Simulation Study. Simulation Monographs, Pudoc, Wageningen, the Netherlands.

Goudriaan J (1982) Some techniques in dynamic simulation. In: Simulation of Plant Growth and Crop Production (eds. FWT Penning de Vries \& HH van Laar), 66-84. Simulation Monographs, Pudoc, Wageningen, the Netherlands.

Kropff MJ (1993) Mechanisms of competition for light. In: Modelling Crop-Weed interactions. (eds. MJ Kropff \& HH Van Laar), 33-62. CAB International and the International Rice Research Institute, Wallingford, UK.

Kropff MJ, \& Lotz LAP (1993) Eco-physiological characterization of the species. In: Modelling CropWeed Interactions (eds. MJ Kropff \& HH Van Laar), 83-104. CAB International and the International Rice Research Institute, Wallingford, UK.

Kropff MJ, \& Spitters CJT (1992) An eco-physiological model for interspecific competition, applied to the influence of Chenopodium album L. on sugar beet. I. Model description and parameterization. Weed Research 32, 437-450.

Kropff MJ, Moody K, Lindquist JL, Migo TR, \& Fajardo FF (1994) Models to predict yield loss due to weeds in rice ecosystems. Philippine Journal of Weed Science (Special issue), 29-44.

Kropff MJ, \& Van Laar HH (1993) Modelling crop-weed interactions. CAB International and the International Rice Research Institute, Wallingford, UK.

Lawlor DW (1995) Photosynthesis, productivity and environment. Journal of Experimental Botany 46 (Special issue), 1449-1461. 
Lindquist JL, \& Kropff MJ (1996) Applications of an ecophysiological model for irrigated rice (Oryza sativa) -Echinochloa competition. Weed Science 44, 52-56.

Lindquist JL, \& Mortensen DA (1997) A simulation approach to identifying the mechanisms of maize tolerance to velvetleaf competition for light. In: Proceedings 1997 Brighton Crop Protection Conference - Weeds, Brighton, 503-508.

Louwerse W, Sibma L, \& Van Kleef J (1990) Crop photosynthesis, respiration and dry matter production in maize. Netherlands Journal of Agricultural Science 38, 95-108.

McCullough DE, Aguilera A, \& Tollenaar M (1994) N uptake, N partitioning, and photosynthetic $\mathrm{N}$-use efficiency of an old and a new maize hybrid. Canadian Journal of Plant Science 74, 479-484.

Nelson LA, Holshouser DL, Elmore RW, Nordquist PT, Klein RN, \& Baltensperger DD (1993) Nebraska Corn Hybrid Tests. Extension Circular 93-105. University of Nebraska Cooperative Extension Service, Lincoln NE.

Regnier EE, \& Stoller EW (1989) The effects of soybean (Glycine max) interference on the canopy architecture of common cocklebur (Xanthium strumarium), Jimsonweed (Datura stramonium), and velvetleaf (Abutilon theophrasti). Weed Science 37, 187-195.

Regnier EE, Salvucci ME, \& Stoller EW (1988) Photosynthesis and growth responses to irradiance in soybean (Glycine max) and three broadleaf weeds. Weed Science 36, 487-496.

SAS Institute (1986) SAS System for Linear Models. SAS Institute Cary, NC, USA.

Sinclair TR, \& Horie T (1989) Leaf nitrogen, photosynthesis, and crop radiation use efficiency: A review. Crop Science 29, 90-98.

Sinoquet H, \& Caldwell RM (1995) Estimation of light capture and partitioning in intercropping systems. In: Ecophysiology of Tropical Intercropping (eds. H Sinoquet \& P Cruz), 79-80. Institut National de la Recherche Agronomique, Paris.

Tremmel DC, \& Bazzaz FA (1995) Plant architecture and allocation in different neighborhoods: Implications for competitive success. Ecology 76, 262-271. 